\title{
Heterologous complementation of a pyrF deletion in Caldicellulosiruptor hydrothermalis generates a new host for the analysis of biomass deconstruction
}

Joseph Groom ${ }^{1,2}$, Daehwan Chung ${ }^{1,2}$, Jenna Young ${ }^{1,2}$ and Janet Westpheling ${ }^{1,2^{*}}$

\begin{abstract}
Background: Members of the thermophilic, anaerobic Gram-positive bacterial genus Caldicellulosiruptor grow optimally at 65 to $78^{\circ} \mathrm{C}$ and degrade lignocellulosic biomass without conventional pretreatment. Decomposition of complex cell wall polysaccharides is a major bottleneck in the conversion of plant biomass to biofuels and chemicals, and conventional biomass pretreatment includes exposure to high temperatures, acids, or bases as well as enzymatic digestion. Members of this genus contain a variety of glycosyl hydrolases, pectinases, and xylanases, but the contribution of these individual enzymes to biomass deconstruction is largely unknown. C. hydrothermalis is of special interest because it is the least cellulolytic of all the Caldicellulosiruptor species so far characterized, making it an ideal naïve system to study key cellulolytic enzymes from these bacteria.
\end{abstract}

Results: To develop methods for genetic manipulation of $C$. hydrothermalis, we selected a spontaneous deletion of pyrF, a gene in the pyrimidine biosynthetic pathway, resulting in a strain that was a uracil auxotroph resistant to 5-fluoroorotic acid (5-FOA). This strain allowed the selection of prototrophic transformants with either replicating or non-replicating plasmids containing the wild-type pyrF gene. Counter-selection of the pyrF wild-type allele on non-replicating vectors allowed the construction of chromosomal deletions. To eliminate integration of the non-replicating plasmid at the pyrF locus in the C. hydrothermalis chromosome, we used the non-homologous Clostridium thermocellum wild-type pyrF allele to complement the $C$. hydrothermalis pyrF deletion. The autonomously replicating shuttle vector was maintained at 25 to 115 copies per chromosome. Deletion of the Chyl restriction enzyme in C. hydrothermalis increased the transformation efficiency by an order of magnitude and demonstrated the ability to construct deletions and insertions in the genome of this new host.

Conclusions: The use of $C$. hydrothermalis as a host for homologous and heterologous expression of enzymes important for biomass deconstruction will enable the identification of enzymes that contribute to the special ability of these bacteria to degrade complex lignocellulosic substrates as well as facilitate the construction of strains to improve and extend their substrate utilization capabilities.

\footnotetext{
* Correspondence: janwest@uga.edu

${ }^{1}$ Department of Genetics, University of Georgia, Athens, GA 30602, USA

${ }^{2}$ The BioEnergy Science Center, Oak Ridge National Laboratory, Oak Ridge,

TN, USA
}

\section{Biomed Central}

(c) 2014 Groom et al.; licensee BioMed Central Ltd. This is an Open Access article distributed under the terms of the Creative Commons Attribution License (http://creativecommons.org/licenses/by/4.0), which permits unrestricted use, distribution, and reproduction in any medium, provided the original work is properly credited. The Creative Commons Public Domain Dedication waiver (http://creativecommons.org/publicdomain/zero/1.0/) applies to the data made available in this article unless otherwise stated. 


\section{Introduction}

Plant biomass recalcitrance is one of the most important barriers to its use as a substrate for the production of fuels and chemicals using microorganisms as catalysts. The plant cell wall consists of a complex web of polysaccharides and phenolics that function in plant structure and development [1]. Perennial plants like switchgrass could be incorporated into so-called agro-ecosystems, which would increase carbon storage and biofuel production, decrease carbon dioxide emissions, and improve water quality through wetland denitrification [2]. While the natural recalcitrance of plant biomass is a major barrier [3], several methods including direct microbial breakdown of cell wall structures can be used to liberate energy-rich sugars for conversion to useful biofuels and bioproducts.

Chemical and thermal pretreatments are often used to break down the raw substrate, but they are expensive and destructive to the sugars in the biomass [4], and they produce hydrolysates inhibitory to both cellulose degradation and microbial growth [5]. In contrast, thermophilic anaerobes in the genus Caldicellulosiruptor can deconstruct high loadings of plant biomass into simple sugars without conventional pretreatment [6-8] and have recently been engineered to produce ethanol directly from switchgrass [9]. Caldicellulosiruptor species can simultaneously utilize the wide range of hexoses, pentoses, oligosaccharides, and polysaccharides released from the plant cell wall, and there is no evidence of carbon catabolite repression [10,11]. These qualities make them well suited for consolidated bioprocessing (CBP), in which one microorganism is used for both biomass deconstruction and end-product formation.

Members of the Caldicellulosiruptor genus are anaerobic Gram-positive bacteria, and they are the most thermophilic cellulose-degrading organisms known [12]. They secrete free carbohydrate-active enzymes (CAZys) [13] with carbohydrate-binding modules that are well suited for binding and degrading cell wall polysaccharides [14]. C. bescii is one of the strongest crystalline cellulose degraders in the genus, whereas the closely related $C$. hydrothermalis is one of the weakest [7]. Interestingly, $C$. hydrothermalis lacks the multidomain CAZys found in more cellulolytic members of the genus [15] as well as a cluster of pectinases that affect $C$. bescii growth on biomass (D. Chung, submitted). In addition to lacking multidomain enzymes, $C$. hydrothermalis completely lacks the glycosyl hydrolase $(\mathrm{GH})$ domains GH9 and GH48 [12], the domains that comprise CelA, the most highly secreted cellulase in C. bescii [16]. C. hydrothermalis thus provides a "blank slate" with which to study thermophilic enzymes important for biomass degradation in vivo, and is a promising system for heterologous expression of plant biomass deconstruction enzymes.
To establish methods for genetic manipulation of C. hydrothermalis, we took an approach similar to the one previously used for $C$. bescii that relied on the selection of a pyrF deletion mutant, which allows for nutritional selection of transformants [17]. Interestingly, C. hydrothermalis contains fewer mobile genetic elements than other members of the genus [18], so this species may have other advantages for genetic manipulation, including fewer issues with genome stability that could result from genetic selections and counter-selections. We transformed the pyrF deletion mutant with the PJGW07 shuttle vector that is based on a native plasmid, pBAS2, from C. bescii [19]. Both the $C$. bescii and the heterologous Clostridium thermocellum wild-type pyrF allele were shown to complement this deletion, restoring the mutant to uracil prototrophy. Deletion of the Chyl restriction enzyme in C. hydrothermalis, a homolog of a HaeIII-like restriction enzyme known to be a barrier to transformation in $C$. bescii $[20,21]$, increased the transformation efficiency by about an order of magnitude. The new strain $C$. hydrothermalis JWCH008 should facilitate the assessment of plant biomass deconstruction by the Caldicellulosiruptor genus and the molecular engineering of deconstruction enzymes.

\section{Results and discussion}

Selection for resistance to 5-FOA resulted in a spontaneous deletion of the pyrF gene in C. hydrothermalis

The pyrF gene encodes orotidine monophosphate decarboxylase, an enzyme in the pyrimidine biosynthesis pathway. Deletion of this gene results in uracil auxotrophy and resistance to 5-fluoroorotic acid (5-FOA), allowing prototrophic selection of transformants and counter-selection of the wild-type allele [22]. The optimal growth temperature for C. hydrothermalis is $65^{\circ} \mathrm{C}$ [23], and we had previously observed an increase in the spontaneous mutation rate in cells grown above and below $65^{\circ} \mathrm{C}$. To obtain spontaneous deletions of pyrF, cells were grown at nonoptimal temperatures in the presence of uracil. The presence of uracil in the growth medium allowed for the maintenance of cells with spontaneous mutations in the pyrF gene. After growth at various temperatures, cells were plated onto a medium with 5 -FOA selecting resistance and loss of pyrF function. One 5-FOA resistant mutant, JWCH006 (Table 1), that had been grown at $60^{\circ} \mathrm{C}$ contained a 99-bp deletion in pyrF (Figure 1A) and was confirmed to be a uracil auxotroph resistant to 5-FOA.

\section{Uracil auxotrophy in C. hydrothermalis is complemented by heterologous expression of the Clostridium thermocellum pyrF gene}

Electrocompetent $C$. hydrothermalis JWCH006 ( $\triangle p y r F)$ cells were prepared based on the method for $C$. bescii [17] and transformed with a previously described shuttle vector, pDCW89 [24], containing the wild-type C. bescii 
Table 1 Strains and plasmids used in this study

\begin{tabular}{|c|c|}
\hline Strain or plasmid & Genotype/phenotype \\
\hline JWCH0O1 & $\begin{array}{l}\text { C. hydrothermalis DSM } 18901 \text { wild -type } \\
\left(\text { ura }^{+} / 5-\mathrm{FOA}^{\mathrm{S}}\right)\end{array}$ \\
\hline JWCH006 & C. hydrothermalis $\Delta \mathrm{pyrF}\left(\right.$ ura $\left.^{-} / 5-\mathrm{FOA}^{\mathrm{R}}\right)$ \\
\hline JWCH0O8 & C. hydrothermalis $\Delta$ pyrF $\Delta$ chyl $\left(u_{r a}^{-} / 5-\mathrm{FOA}^{\mathrm{R}}\right)$ \\
\hline JWCH009 & $\begin{array}{l}\text { C. hydrothermalis } \Delta \text { pyrF harboring pJGW07 } \\
\left(u^{\prime} a^{+} / 5-F^{S}\right)\end{array}$ \\
\hline JW401 & DH5a containing pJGW03 (Apramycin $\left.{ }^{R}\right)$ \\
\hline JW402 & DH5a containing pJGW07 (Apramycin ${ }^{R}$ ) \\
\hline pDCW89 & $\begin{array}{l}\text { E. coli/Caldicellulosiruptor shuttle vector } \\
\text { (C. bescii pyrF) }\end{array}$ \\
\hline pDCW88 & $\begin{array}{l}\text { Caldicellulosiruptor non-replicating vector } \\
\text { (C. bescii pyrF) }\end{array}$ \\
\hline pDCW151 & $\begin{array}{l}\text { Caldicellulosiruptor chyl deletion vector } \\
\text { (C. bescii pyrF) }\end{array}$ \\
\hline pJGW03 & $\begin{array}{l}\text { Caldicellulosiruptor chyl deletion vector } \\
\text { (C. thermocellum pyrF) }\end{array}$ \\
\hline pJGW07 & $\begin{array}{l}\text { E. coli/Caldicellulosiruptor shuttle vector } \\
\text { (C. thermocellum pyrF) }\end{array}$ \\
\hline
\end{tabular}

pyrF allele. Transformation of $C$. bescii with plasmid DNA isolated from $E$. coli requires in vitro methylation by a methyltransferase, M.CbeI [17]. As C. hydrothermalis has a similar restriction profile to that of $C$. bescii [20], we anticipated that in vitro methylation by M.CbeI would protect plasmid DNA isolated from E. coli and allow transformation of C. hydrothermalis. pDCW89 DNA methylated with M.CbeI in vitro successfully transformed the C. hydrothermalis $\triangle p y r F$ mutant to prototrophy at an average frequency of 37 colony forming units (CFUs) per microgram of DNA (Table 2).

Since the deletion of pyrF in JWCH006 was only 99 bp (Figure 1A), and there is 95\% DNA sequence homology between the pyrF genes in C. bescii and C. hydrothermalis, there was a large region of residual homology between the pyrF locus in the $C$. hydrothermalis chromosome and the C. bescii pyrF gene on the plasmid. Although pDCW89 DNA methylated in vitro with M.CbeI transformed $C$. hydrothermalis JWCH006 to prototrophy, we found that the wild-type plasmid-encoded pyrF allele repaired the mutant pyrF locus in almost every case (Additional file 1: Figure S1), and the plasmid was not maintained autonomously over time. Since marker replacement in C. hydrothermalis relies on the integration of nonreplicating plasmids at sites other than pyrF, the $C$. bescii pyrF cassette in pDCW89 was replaced by the C. thermocellum homolog (Cthe0951) to create pJGW07 (Figure 2A). While the two PyrF protein sequences are $45 \%$ identical, the $C$. thermocellum pyrF gene has very low DNA sequence homology with the Caldicellulosiruptor pyrF genes. Transformation of JWCH006 with methylated pJGW07 was successful (Figure 2B, Additional file 1: figure S2A), and uracil prototrophic transformants were obtained at a frequency of $22 \pm 10$ CFU per microgram of DNA (Table 2).
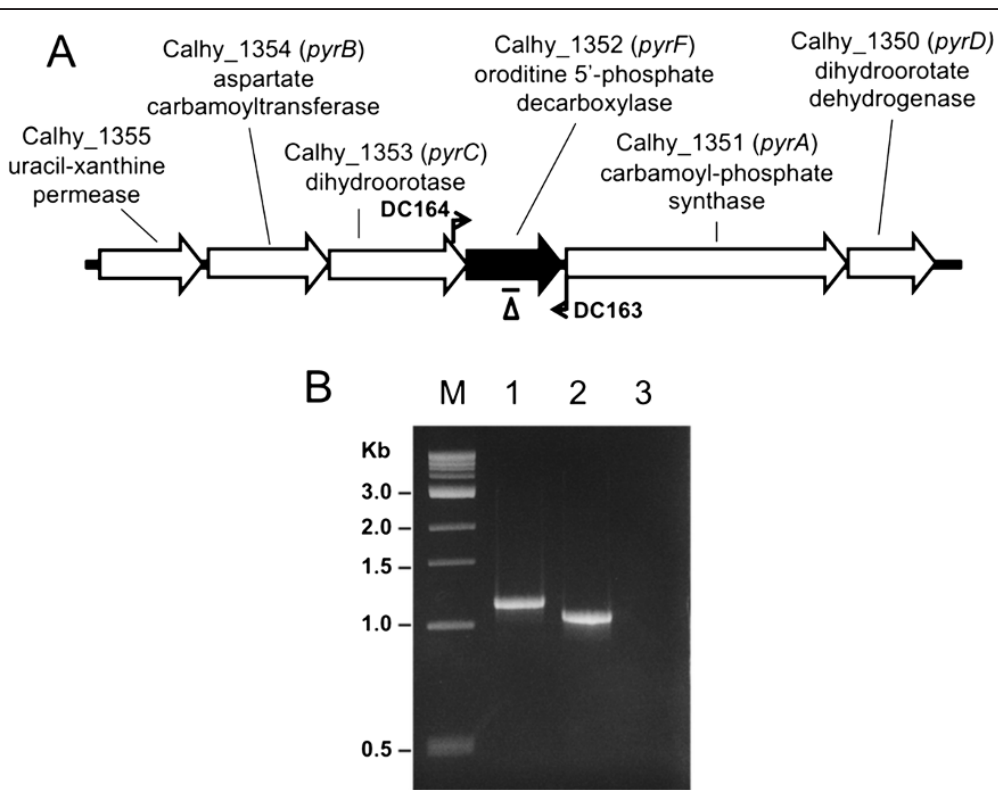

Figure 1 Isolation of a spontaneous pyrF mutant in C. hydrothermalis. (A) Chromosomal map of the uridine monophosphate (UMP) biosynthetic gene cluster in C. hydrothermalis JWCH006. The 99-bp spontaneous deletion in $\Delta p y r F$ is indicated by the line below the diagram. $462 \mathrm{bp}$ lie upstream and $357 \mathrm{bp}$ lie downstream of the deletion. Bent arrows depict primers used to verify the structure of the pyrF gene in the JWCH006 strain. (B) Gel depicting PCR products of the pyrF region in the wild-type strain (1.13 kb) compared to the JWCH006 strain (1.02 kb) amplified by the indicated primers (DC163 and DC164). M: 1 kb DNA ladder (NEB); 1: wild-type genomic DNA; 2: JWCH006 genomic DNA; 3 : negative control. 


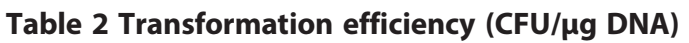

\begin{tabular}{lllll}
\hline Strain & pJGW07 & pJGW07M & pDCW89 & pDCW89M \\
\hline JWCH006 $\Delta$ pyrF & $33 \pm 24$ & $22 \pm 10$ & $18 \pm 20$ & $37 \pm 43$ \\
JWCH008 $\Delta$ pyrF $\Delta$ chyl & $395 \pm 301$ & $241 \pm 174$ & $58 \pm 48$ & $100 \pm 90$
\end{tabular}

The suffix $M$ denotes plasmid methylated with $C$. bescii M.Cbel methyltransferase.

Results represent the average \pm standard deviation of three biologically independent transformation experiments.

Plasmid pJGW07 was purified directly from C. hydrothermalis based on a previously published method for other Gram-positive organisms [25]. Undigested plasmid isolated from $C$. hydrothermalis migrated in an agarose gel slightly differently from plasmid DNA isolated from $E$. coli, and we suggest that the difference is not in size but in methylation within the native host compared to E. coli (Figure 2B). Endonuclease restriction analysis using a panel of enzymes indicated that plasmid isolated from C. hydrothermalis is protected at GGCC sites by a HaeIII-like modification system as expected but not at GATC sites (Additional file 1: Figure S3). This suggests that $C$. hydrothermalis lacks the DNA adenine methylase present in E. coli. EcoRI or $\mathrm{HhaI}$ recognition sites are not protected in either organism.

To confirm that the plasmid was replicating autonomously, DNA isolated from the C. hydrothermalis transformant JWCH009 (Table 1) was back-transformed into E. coli DH5 $\alpha$. Plasmid DNA recovered from 12 apramycin-resistant $E$. coli transformants was identical in its restriction patterns to pJGW07 transformed into C. hydrothermalis, suggesting that the plasmid was structurally stable during transformation, replication, and backtransformation to E. coli (Additional file 1: Figure S2). There was no evidence of plasmid integration (Additional file 1: Figure S4) resulting from recombination between the $C$. thermocellum pyrF gene on the plasmid and the $C$. hydrothermalis pyrF gene in the chromosome.

These data show that, although $C$. thermocellum has an optimal growth temperature of $60^{\circ} \mathrm{C}$, the C. thermocellum orotidine- $5^{\prime}$-phosphate decarboxylase functions at temperatures up to at least $65^{\circ} \mathrm{C}$ and that the C. thermocellum gene is expressed at sufficient levels to complement the $C$. hydrothermalis pyrF deletion.

\section{A shuttle vector derived from a native $C$. bescii plasmid is maintained at a high copy number in $C$. hydrothermalis}

We recently reported the construction of a shuttle vector for C. bescii [24] based on the smaller of two native plasmids in that species [19]. The native plasmid pBAS2 is maintained in $C$. bescii at a copy number of approximately 75 [24]. Because the shuttle vector derived from this plasmid competed with the native plasmid it was derived from, the shuttle vector was maintained in low copy and was readily lost without selection. While an unstable plasmid is useful for some applications, stability and high copy number also have advantages. No native plasmid DNA was detected in C. hydrothermalis using conventional plasmid isolation methods, nor was one identified during the sequencing of total DNA isolated from this strain [26]. We anticipated that the C. bescii shuttle vector would likely replicate in C. hydrothermalis and might be stably maintained at a high copy number. Quantitative polymerase chain reaction (qPCR) was performed as described in the Methods section to determine the copy number of the pJGW07 plasmid in C. hydrothermalis, and the results indicated that it was maintained between 25 and 115 copies per chromosome over five serial transfers, but was quickly lost without selection (Figure 3, Additional file 1: Table S1).
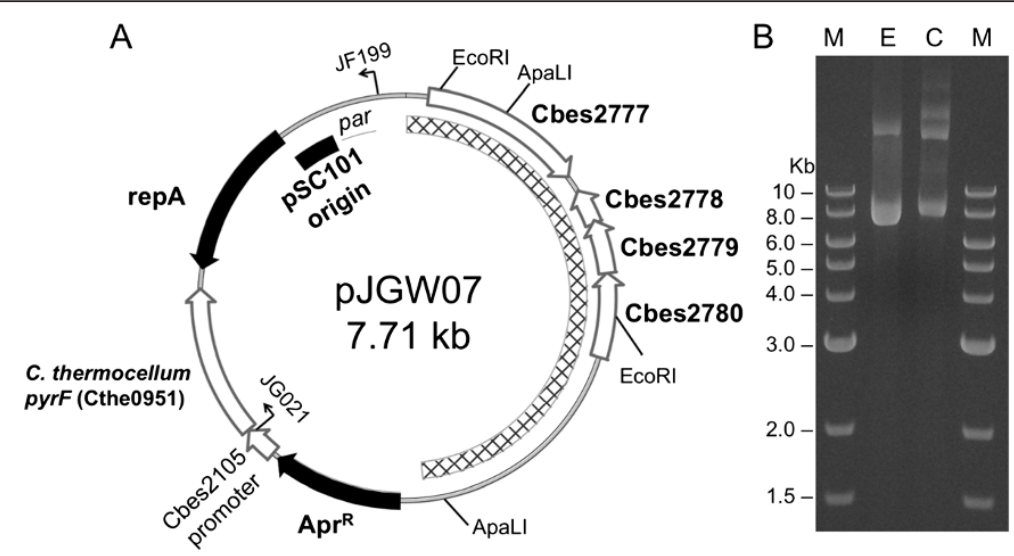

Figure 2 Plasmid pJGW07 isolated directly from C. hydrothermalis $\Delta$ pyrF. (A) pJGW07 constructed by replacing the C. bescii pyrF gene with the C. thermocellum ATCC 4705 homolog Cthe0951. The hatched region was derived from C. bescii native plasmid pBAS2. Apr ${ }^{R}$, apramycin resistance casette; repA, replication initiator for pSC101 replication origin; par, partitioning locus. (B) Agarose gel depicting pJGW07 plasmid DNA extracted from different sources. M, molecular weight standards; E, pJGW07 purified from E. coli; C, pJGW07 purified from C. hydrothermalis. 


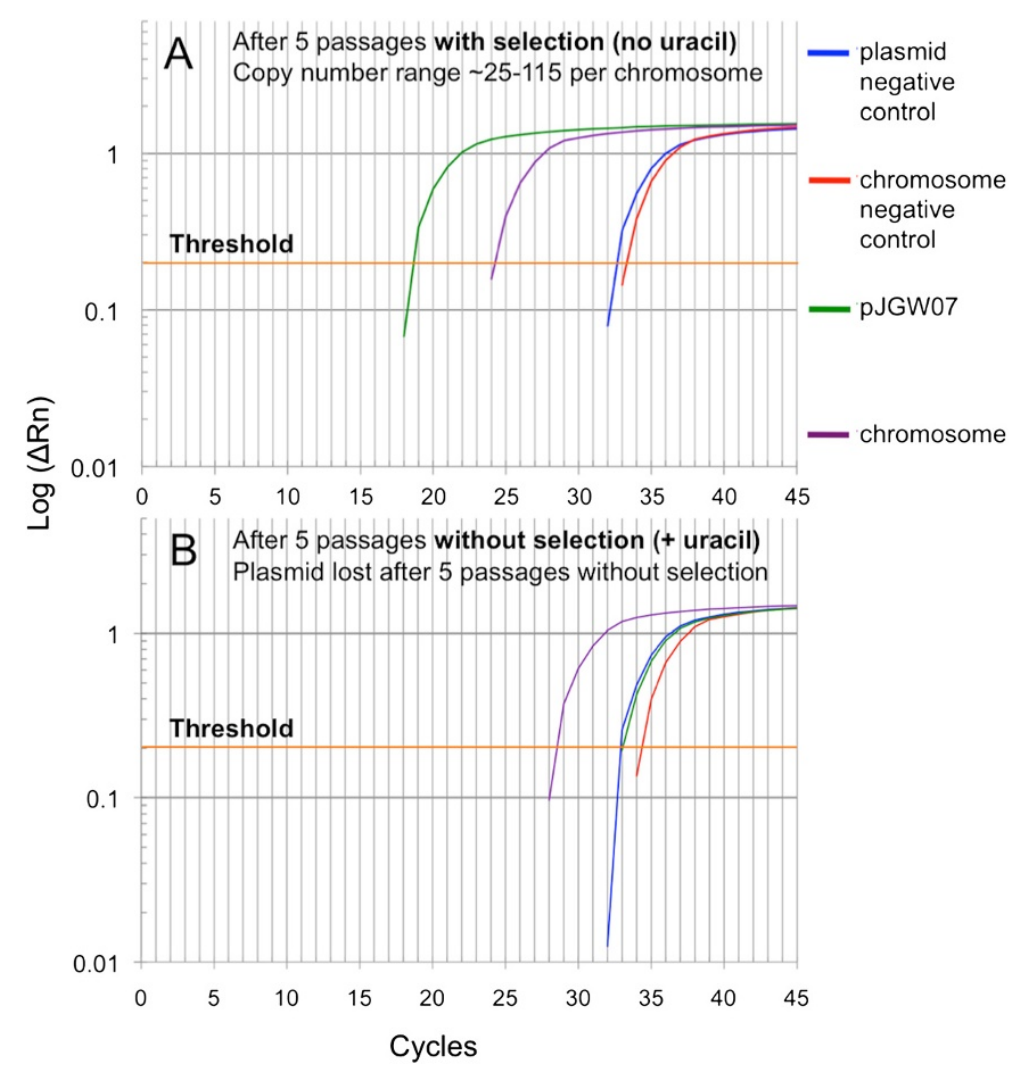

Figure 3 Determination of plasmid copy number. Quantitative PCR (qPCR) was used to detect the copy number of plasmid pJGW07 in relation to the chromosome. Shown are the results after the fifth passage through $\mathbf{A}$ ) selective and $\mathbf{B}$ ) non-selective media. The $x$-axis is the number of iterations of the polymerase chain reaction, and the $y$-axis displays the logarithm of $\Delta R n$, which is the fluorescence of the SYBR green dye with the baseline fluorescence subtracted. The number of cycles required to cross a given threshold (cycles to threshold or $\mathrm{Ct}$ ) is reflective of the plasmid copy number (PCN). The threshold is indicated by a horizontal line. PCN was calculated using the formula PCN $=2 \wedge\left|C t_{\text {chromosome }}-\mathrm{Ct}_{\text {plasmid }}\right|$. The copy number ranged from about 25 to 115 copies per chromosome in the cultures with selective media. The copy number was determined based on two independent biological samples with three technical replicates (Additional file 1: Table S1).

Deletion of the $C$. hydrothermalis Chyl restriction enzyme results in increased transformation efficiency

In developing methods for DNA transformation of C. bescii, we observed that restriction by a HaeIII isoschizomer, CbeI [21], was an absolute barrier to transformation of DNA from E. coli. We identified, cloned, expressed, and purified its cognate methyltransferase, $M$. CbeI, from $C$. bescii and showed that DNA methylated in vitro readily transformed $C$. bescii [17]. Deletion of cbeI in $C$. bescii relieved the requirement for in vitro methylation of plasmid DNA from E. coli by M.CbeI [20] and allowed efficient DNA transformation. The C. hydrothermalis chyI gene is an ortholog of cbeI with 96\% DNA sequence identity and $100 \%$ sequence coverage. A deletion of chyI was constructed on a plasmid, pJGW03, which was transformed into C. hydrothermalis JWCH006 (Figure 4A). A deletion mutant was readily obtained in a screen of 50 colonies, and only two rounds of purification on low osmolarity defined (LOD) plating media containing uracil [27] were required to resolve the merodiploid, resulting in
C. hydrothermalis JWCH008 ( $\Delta p y r F ~ \Delta c h y I)$ (Figure 4C). We note that the region of the $C$. hydrothermalis genome that contains ChyI is not identical to the region of the $C$. bescii chromosome that contains CbeI. The C. hydrothermalis region contains an additional open reading frame (ORF) that apparently encodes a truncated form of the Nterminal portion of the ChyI protein. Sequence analysis revealed a premature stop codon likely resulting from a point mutation in the ChyI ORF. This altered gene structure had no obvious effect on enzyme function in vivo. The deletion we designed included both ORFs.

To assess whether the loss of the Chyl restriction enzyme resulted in an increase in transformation efficiency in C. hydrothermalis, we compared the transformation efficiencies of the two strains generated in this study, JWCH006 ( $\Delta p y r F)$ and JWCH008 ( $\Delta p y r F \Delta c h y I)$. As shown in Table 2, electrotransformation of the JWCH006 parent strain with either the pJGW07 shuttle vector containing the $C$. thermocellum pyrF gene, or the pDCW89 vector containing the $C$. bescii pyrF gene, was low but 


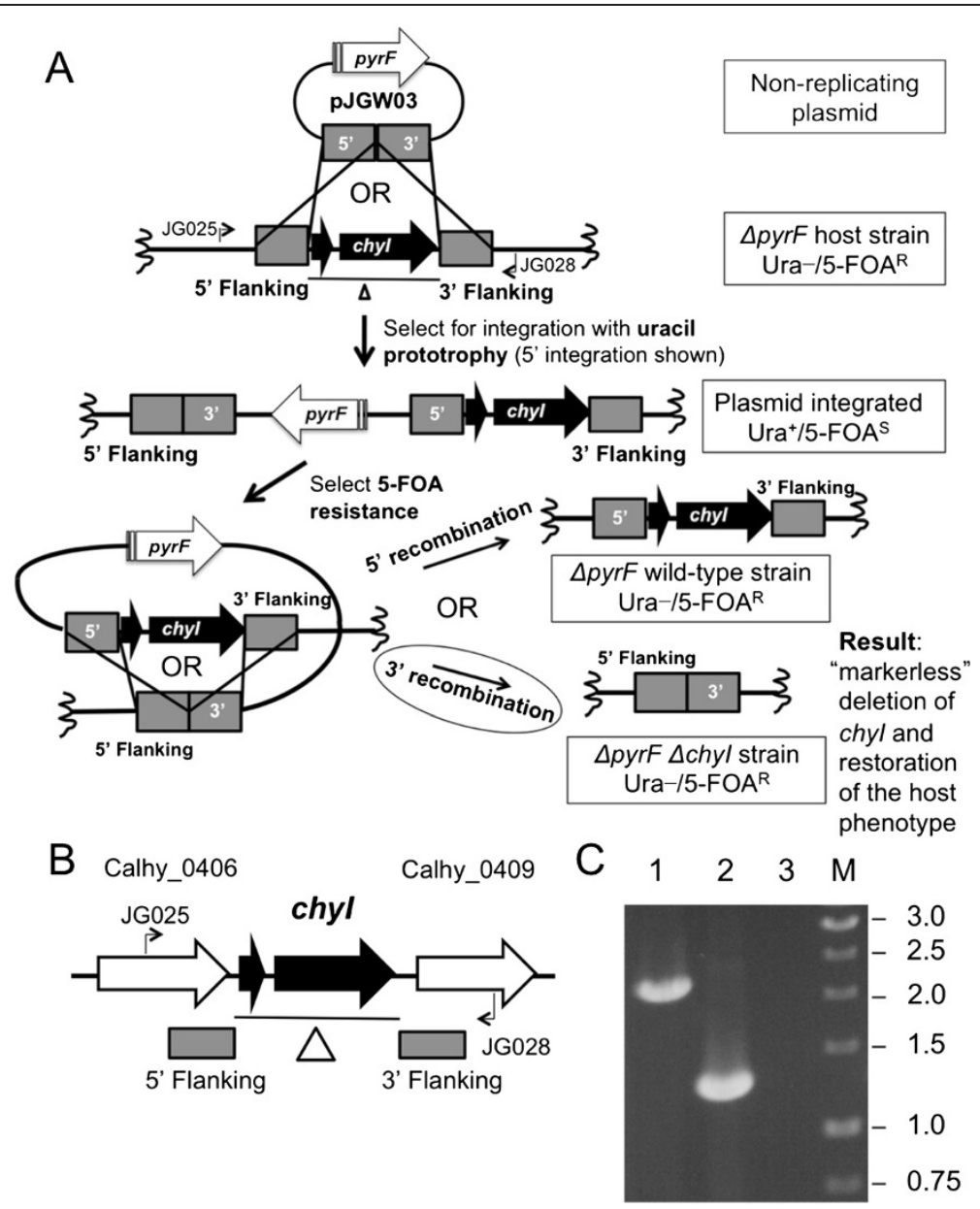

Figure 4 Deletion of the gene encoding putative restriction enzyme Chyl. A) Scheme for targeted gene deletion. The pJGW03 chyl knockout vector is transformed into JWCH006 ( $\triangle p y r F)$, and uracil prototrophy selects for integration at one of the 500-bp flanking regions, denoted by the gray boxes. $5^{\prime}$ integration is shown. The uracil prototroph is then plated on 5-FOA to select for loop-out of the pyrF cassette via homologous recombination between flanking region sequences. The two possible results are a return to the wild-type sequence or a clean chyl deletion. (B) Chromosomal map of the locus containing the ORF for chyl. The deleted region is indicated by the line below the diagram. Bent arrows depict primers used to verify deletion of chyl in the JWCH008 strain. (C) Gel depicting PCR products of the chyl region in the JWCH006 $\triangle p y r F$ strain (2.3 kb) compared to the JWCH008 $\Delta$ pyrF $\Delta$ chyl strain (1.25 kb) amplified by the indicated primers (JG025 and JG028). 1: C. hydrothermalis JWCH006 genomic DNA; 2: C. hydrothermalis JWCH008 genomic DNA; 3: negative control; M: 1 kb DNA ladder (NEB).

detectable, and methylation of plasmid DNA did not make a significant difference in transformability. The standard deviation in experiments with low numbers of transformants is substantial but not unexpected [28]. This extremely low transformation efficiency may be an underestimate of the actual efficiency, as the plating efficiency of $C$. hydrothermalis on a selective solid medium is less than $10^{-4}$ (plating $10^{6}$ cells as determined by cell count resulted in fewer than 100 colonies). Transformation of JWCH008 containing the chyI deletion was an order of magnitude higher than that of JWCH006, and again, there is no significant difference between the transformation efficiency of methylated and unmethylated DNA, suggesting differences in the restriction/modification systems of C. hydrothermalis and C. bescii. The fact that methylation with M.CbeI made no difference in transformation efficiency was somewhat surprising, especially considering the fact that deletion of ChyI increased the transformation frequency of unmethylated DNA. We interpret this to indicate that there are differences between $C$. bescii and C. hydrothermalis in their restriction/modification systems and perhaps additional enzymes in one or the other that account for the differences in transformation frequencies. It is also possible that the truncated form of the CbeI/ChyI orthologous proteins makes a difference in their activities (Figure 4B). We previously reported that $C$. hydrothermalis chromosomal DNA is resistant to digestion by BamHI and BspEI [20]. Both these enzymes have six base recognition sequences that are relatively rare compared to four base recognition sequences. The plasmids used in this 
study do not contain BamHI sites. While there are two BspEI restriction sites (TCCGGA), E. coli DH5 $\alpha$, the strain we used to make plasmid DNA, contains an adenine methyltransferase known to protect this site and may prevent cleavage by $C$. hydrothermalis during DNA transformation.

We emphasize that the observed transformation of the JWCH006 parent strain is not an indication that C. hydrothermalis is naturally competent for DNA uptake. Preparation of electrocompetent cells and electroporation was necessary to detect transformation. We have invested some effort to induce natural competence in members of this genus, but those efforts have not been successful. There are homologs to the natural competence genes comEA, comEC, comGC, and dprA [29], but in contrast to other thermophilic anaerobes [30], there is no evidence to date of natural competence in Caldicellulosiruptor species.

\section{Conclusions}

Methods for genetic manipulation of C. hydrothermalis, based on those used for $C$. bescii, were successful and efficient. Restriction of DNA was not an absolute barrier to transformation, but deletion of the Chyl restriction enzyme in $C$. hydrothermalis increased the transformation efficiency by an order of magnitude. Heterologous expression of the Clostridium thermocellum pyrF gene was sufficient to complement the $C$. hydrothermalis $\Delta p y r F$ mutant, allowing both autonomous plasmid replication at relatively high copy (about 25 to 115 copies/ chromosome) and marker replacement of the chyI gene in the $C$. hydrothermalis chromosome. The use of this new strain, C. hydrothermalis JWCH008, should allow for the expression of heterologous and homologous enzymes for both the identification and analysis of enzymes involved in biomass deconstruction of unpretreated plant biomass by the Caldicellulosiruptor genus. It will also enable the engineering of glycosyl hydrolases such as CelA and other important plant biomass deconstruction enzymes in a strain devoid of similar enzymes or activities.

\section{Methods}

\section{Selection of a pyrF deletion}

Wild-type C. hydrothermalis DSM 18901 was grown from a $0.5 \%$ inoculum in $50 \mathrm{~mL}$ of a low osmolarity defined growth medium (LOD) supplemented with $40 \mu \mathrm{M}$ uracil. Cultures were grown at $55^{\circ} \mathrm{C}, 60^{\circ} \mathrm{C}, 68^{\circ} \mathrm{C}$, and $75^{\circ} \mathrm{C}$. Cells in the late exponential phase were cooled to room temperature, harvested by centrifugation at 6,100 $\times$ g, and resuspended in $1 \mathrm{X} \mathrm{C}$. bescii partial base salts [6]. $100 \mu \mathrm{L}$ of resuspended cells were mixed with a $1.5 \%$ agar overlay and plated onto LOD media with $40 \mu \mathrm{M}$ uracil and $8 \mathrm{mM}$ 5 -FOA. The plates were degassed in anaerobic chambers and incubated for 4 days at $68^{\circ} \mathrm{C}$. The colonies were picked directly into $20 \mathrm{~mL}$ LOD media with $40 \mu \mathrm{M}$ uracil, which was immediately degassed and incubated at $68^{\circ} \mathrm{C}$. When the media was turbid, chromosomal DNA was extracted with a Zymo Research gDNA Extraction kit (Irvine, CA). The pyrF gene region was amplified from the wild type and deletion mutant with primers DC163 and DC164 (Figure 1A), and the PCR products were analyzed for the presence of deletions in a $1.5 \% \mathrm{w} / \mathrm{v}$ agarose gel by electrophoresis (Figure 1B). All plasmids were verified by DNA sequencing (GENEWIZ).

\section{Construction of a shuttle vector containing the pyrF gene from Clostridium thermocellum ATCC 27405}

High-Fidelity Q5 Polymerase (New England Biolabs (NEB), Ipswich, MA), restriction enzymes (NEB), and Fast-Link $^{\mathrm{TM}}$ DNA Ligase (Epicentre Technologies, Madison, WI) were used according to manufacturer instructions. pJGW07 (Figure 2A) was constructed by replacing the C. bescii pyrF gene (Cbes1377) on the replicating shuttle vector pDCW89 [24] with the Clostridium thermocellum homolog for pyrF (Cthe0951). Cthe0951 was amplified by PCR using primers JG021 and JG022, engineered to contain XbaI and NcoI restriction sites, respectively. This 945-bp PCR product was ligated directionally to a $6.75-\mathrm{kb}$ pDCW89 PCR product amplified using primers JG023 and JG024, which also contain XbaI and NcoI sites. Correct clones were purified from $E$. coli with a Miniprep kit (Qiagen), and confirmed by restriction fragment analysis and DNA sequencing (GENEWIZ).

\section{Transformation of $\mathrm{C}$. hydrothermalis JWCH006}

To prepare cells for transformation, $15 \mathrm{~mL}$ of a freshly grown JWCH006 ( $\triangle p y r F)$ culture were inoculated into four 500-mL bottles of fresh LOD supplemented with $40 \mu \mathrm{M}$ uracil and 19 amino acids, and incubated at $65^{\circ} \mathrm{C}$ to the early exponential phase $\left(\mathrm{OD}_{680}\right.$ approximately 0.04 to 0.05$)$. The cultures were cooled to room temperature for $1 \mathrm{~h}$, harvested by centrifugation $(5,000 \times \mathrm{g}, 10 \mathrm{~min})$ at $4^{\circ} \mathrm{C}$ and washed three times with $50 \mathrm{~mL}$ pre-chilled $10 \%$ sucrose. After the final wash, the cell pellets were resuspended in about $250 \mu \mathrm{L}$ pre-chilled $10 \%$ sucrose. $60-\mu \mathrm{L}$ aliquots of competent JWCH006 were added to plasmid DNA $(0.5 \mu \mathrm{g})$, either methylated with M.CbeI methyltransferase, as previously described [17], or unmethylated, gently mixed, and incubated in $10 \%$ sucrose for $15 \mathrm{~min}$ at room temperature. Electrotransformation of the cell/DNA mixture was performed via a single exponentially decaying electric pulse $(1.8 \mathrm{kV}, 350 \Omega$, and 25 microF) in a prechilled 1-mm cuvette using a Bio-Rad Gene Pulser (Bio-Rad, Hercules, CA). After pulsing, the cells were incubated in $10 \mathrm{~mL}$ low osmolarity complex growth medium (LOC) [27] at $65^{\circ} \mathrm{C}$. After $4 \mathrm{~h}$, the cultures growing in LOC medium were cooled to room temperature, harvested by centrifugation $(6,100 \times \mathrm{g}, 10 \mathrm{~min})$, and 
washed three times at room temperature with $1 \mathrm{X} C$. bescii partial base salts [6] to remove the rich media. The cells were finally resuspended in $800 \mu \mathrm{L} 1 \mathrm{X}$ base salts. For each plate, $100 \mu \mathrm{L}$ of resuspended cells were mixed with $2 \mathrm{~mL}$ of a $1 \%$ agar overlay and plated onto LOD media lacking uracil to select for transformation. The plates were degassed in anaerobic chambers and incubated for 4 days at $65^{\circ} \mathrm{C}$. The colonies were picked directly into $20 \mathrm{~mL}$ LOD media without uracil, which was immediately degassed and incubated at $65^{\circ} \mathrm{C}$. Uracil-prototrophic transformants were confirmed by PCR amplification of C. hydrothermalis DNA using primers JG021 and JF199, which are specific for pJGW07 (Figure 2C, Additional file 1: figure S2A).

\section{Analysis of plasmid structure and stability in C. hydrothermalis}

A single transformant colony was picked directly into $20 \mathrm{~mL}$ LOD media lacking uracil, which was immediately degassed and incubated at $65^{\circ} \mathrm{C}$. This strain maintaining the pJGW07 shuttle vector was named JWCH009. JWCH009 was grown to the late exponential phase $\left(\mathrm{OD}_{680}\right.$ approximately 0.15$)$ in $50 \mathrm{~mL}$ LOD. Direct extraction of plasmid DNA from JWCH009 was performed as previously described $[21,25]$. The plasmid DNA was digested with enzymes HaeIII, EcoRI, HhaI, and MboI (NEB).

To determine the structural stability of the plasmid, DNA was extracted from $C$. hydrothermalis with a gDNA Extraction kit (Zymo Research), and $2 \mu \mathrm{L}$ of DNA was electrotransformed into E. coli $\mathrm{DH} 5 \alpha$ via single electric pulse $(2.5 \mathrm{kV}, 200 \Omega$, and 25 microF) in a pre-chilled 2-mm cuvette using a Bio-Rad Gene Pulser. The cells were placed into $1 \mathrm{~mL}$ SOC media for $1 \mathrm{~h}$ with shaking at $37^{\circ} \mathrm{C}$, and then plated onto LB agar supplemented with $50 \mu \mathrm{g} / \mathrm{mL}$ apramycin. The colonies were picked into $10 \mu \mathrm{mL} \mathrm{LB}$ with $50 \mu \mathrm{g} / \mathrm{mL}$ apramycin, and the plasmid DNA was extracted using a Miniprep kit (Qiagen) and screened with restriction enzymes EcoRI and ApaLI (NEB) (Additional file 1: Figure S2B).

\section{Plasmid copy number determination by quantitative PCR}

To determine the PJGW07 copy number and maintenance over time, JWCH009 was grown to $\mathrm{OD}_{680}$ approximately 0.15 and serially subcultured for 5 days. The total DNA was isolated from the cultures and treated with RNase A. qPCR experiments were carried out with a LightCycler 480 Real-Time PCR instrument (Roche, Indianapolis, IN) with LightCycler 480 SYBR Green I Master mix (Roche). Two independent sets of primers specific to either the pJGW07 plasmid (Q1/Q2 inside Cbes2777, Q3/Q4 inside Cbes2778) or the C. hydrothermalis chromosome (Q11/ Q12 inside Calhy0897, Q13/Q14 inside Calhy1377) were used to compute the relative copy number of the plasmid to the chromosome. Three replicate reactions for each primer set were performed, and the average of the two primer sets on each sample was used to calculate the plasmid copy number in each serial subculture (Additional file 1: Table S1) according to the method of Lee et al. [31]. The amplification efficiency over a $10^{4}$-fold range of DNA concentrations was $93.5 \%$, within the ratio of 90 to $110 \%$ considered acceptable (Life Technologies).

\section{Construction of a deletion of the chyl gene in C. hydrothermalis}

A vector backbone was amplified from suicide vector pDCW88 [20] with primers DC081 and DC262. Flanking regions for the chyI gene (Calhy0408) were amplified using primers DC484 and DC485 (5' flanking region) and DC486 and DC487 (3' flanking region). The $5^{\prime}$ and $3^{\prime}$ flanking regions were combined into one fragment by overlap extension PCR and ligated into the pDCW88 vector backbone using restriction enzymes KpnI and ApaLI. The resulting plasmid pDCW151 was used to construct pJGW03 in which the C. bescii pyrF gene cassette (Cbes1377) was replaced with the C. thermocellum pyrF gene (Cthe0951) as described above. Competent $C$. hydrothermalis JWCH006 cells were prepared as described above. $1.0 \mu \mathrm{g}$ of non-replicating plasmid pJGW03 was added to 50- $\mu \mathrm{L}$ aliquots of competent JWCH006, gently mixed, and incubated for $15 \mathrm{~min}$ at room temperature. Electrotransformation of the cell/DNA mixture was performed via a single electric pulse $(1.8 \mathrm{kV}, 350 \Omega$, and 25 microF) in a pre-chilled 1-mm cuvette using a Bio-Rad Gene Pulser. After pulsing, the cells were incubated in $10 \mathrm{~mL}$ low osmolarity complex growth medium (LOC) [27] at $68^{\circ} \mathrm{C}$ with shaking at $150 \mathrm{rpm}$. From this culture, $0.5 \%$ inocula were transferred into LOD medium lacking uracil at $65^{\circ} \mathrm{C}$ every hour for $4 \mathrm{~h}$ to select for integration into the $C$. hydrothermalis genome. When the cultures in the selective media were turbid, a $0.5 \%$ inoculum was transferred to $50 \mathrm{~mL}$ LOD supplemented with $40 \mu \mathrm{M}$ uracil to allow a loopout of the wild-type pyrF allele to occur. This culture was then plated onto LOD plates supplemented with $40 \mu \mathrm{M}$ uracil and $6 \mathrm{mM}$ 5-FOA to select against the pyrF wild-type allele, and grown for 4 days at $68^{\circ} \mathrm{C}$. Colonies were picked directly into $20 \mathrm{~mL}$ LOD medium with uracil, which was immediately degassed and incubated at $68^{\circ} \mathrm{C}$. The resulting cultures were screened for a deletion using primers JG025 and JG026, and one deletion culture was purified twice on solid LOD media supplemented with $40 \mu \mathrm{M}$ uracil.

\section{Additional file}

Additional file 1: Figure S1. Repair of the pyrF gene in pDCW89 transformants. Figure S2. Evidence for transformation and stable replication of the Caldicellulosiruptor/E. coli shuttle vector pJGW07 in 
C. hydrothermalis. Figure S3. Restriction digest analysis of pJGW07. Figure S4. Maintenance of the mutated pyrF gene in pJGW07 transformants. Table S1. Quantitative PCR data. Table S2. Primers used in this study.

\section{Competing interests}

The authors declare that there are no competing interests.

\section{Authors' contribution}

$J G$ carried out experiments, led the work and contributed to the writing of the manuscript. DC carried out experiments, contributed to the design of experiments and contributed to the writing of the manuscript. JY carried out experiments and contributed to the writing of the manuscript. JW participated in the design of the experiments, led the work and contributed to the writing of the manuscript. All authors read and approved the final manuscript.

\section{Acknowledgements}

We thank Jennifer Copeland for her expert technical assistance. JG was supported by a Presidential Fellowship from the University of Georgia Research Foundation. The BioEnergy Science Center is a U.S. Department of Energy Bioenergy Research Center supported by the Office of Biological and Environmental Research in the DOE Office of Science.

Received: 23 June 2014 Accepted: 28 August 2014

Published online: 16 September 2014

\section{References}

1. Albersheim P, Darvill A, Roberts K, Sederoff R, Staehelin A: Plant Cell Walls. New York: Garland Sci; 2011.

2. Jordan N, Boody G, Broussard W, Glover JD, Keeney D, McCown BH, Mclsaac G, Muller M, Murray H, Neal J, Pansing C, Turner RE, Warner K, Wyse D: Environment. Sustainable development of the agricultural bio-economy. Science 2007, 316(5831):1570-1571.

3. Himmel ME, Ding SY, Johnson DK, Adney WS, Nimlos MR, Brady JW, Foust TD: Biomass recalcitrance: engineering plants and enzymes for biofuels production. Science 2007, 315(5813):804-807.

4. Barakat A, Monlau F, Steyer JP, Carrere H: Effect of lignin-derived and furan compounds found in lignocellulosic hydrolysates on biomethane production. Bioresour Technol 2012, 104:90-99.

5. Hsu T: Chap. 10: Pretreatment of biomass. In Handbook on Bioethanol: Production and Utilization. Edited by Wyman C. London: Taylor \& Francis; 1996.

6. Yang SJ, Kataeva I, Hamilton-Brehm SD, Engle NL, Tschaplinski TJ, Doeppke C, Davis M, Westpheling J, Adams MW: Efficient degradation of lignocellulosic plant biomass, without pretreatment, by the thermophilic anaerobe "Anaerocellum thermophilum" DSM 6725. Appl Environ Microbiol 2009, 75(14):4762-4769.

7. Blumer-Schuette SE, Giannone RJ, Zurawski JV, Ozdemir I, Ma Q, Yin Y, Xu Y, Kataeva I, Poole FL 2nd, Adams MW, Hamilton-Brehm SD, Elkins JG, Larimer FW, Land ML, Hauser L, Cottingham RW, Hettich RL, Kelly RM: Caldicellulosiruptor core and pangenomes reveal determinants for noncellulosomal thermophilic deconstruction of plant biomass. J Bacterio/ 2012, 194(15):4015-4028

8. Basen M, Rhaesa AM, Kataeva I, Prybol CJ, Scott IM, Poole FL, Adams MW: Degradation of high loads of crystalline cellulose and of unpretreated plant biomass by the thermophilic bacterium Caldicellulosiruptor bescii. Bioresour Technol 2014, 152:384-392.

9. Chung D, Cha M, Guss AM, Westpheling J: Direct conversion of plant biomass to ethanol by engineered Caldicellulosiruptor bescii. Proc Natl Acad Sci U S A 2014, 111(24):8931-8936.

10. Vanfossen AL, Verhaart MR, Kengen SM, Kelly RM: Carbohydrate utilization patterns for the extremely thermophilic bacterium Caldicellulosiruptor saccharolyticus reveal broad growth substrate preferences. Appl Environ Microbiol 2009, 75(24):7718-7724.

11. Zurawski J, Blumer-Schuette S, Conway J, Kelly R: The extremely thermophilic genus Caldicellulosiruptor: physiological and genomic characteristics for complex carbohydrate conversion to molecular hydrogen. In Microbial BioEnergy: Hydrogen Production, Advances in Photosynthesis and Respiration. Volume 38. Edited by Philippis DZRD. Dordrecht: Springer; 2014.
12. Blumer-Schuette SE, Lewis DL, Kelly RM: Phylogenetic, microbiological, and glycoside hydrolase diversities within the extremely thermophilic, plant biomass-degrading genus Caldicellulosiruptor. Appl Environ Microbiol 2010, 76(24):8084-8092.

13. Cantarel BL, Coutinho PM, Rancurel C, Bernard T, Lombard V, Henrissat B: The Carbohydrate-Active EnZymes database (CAZy): an expert resource for Glycogenomics. Nucleic Acids Res 2009, 37(Database issue):D233-D238.

14. Dam P, Kataeva I, Yang SJ, Zhou F, Yin Y, Chou W, Poole FL 2nd, Westpheling J, Hettich R, Giannone R, Lewis DL, Kelly R, Gilbert HJ, Henrissat $B, X u Y, A d a m s ~ M W:$ Insights into plant biomass conversion from the genome of the anaerobic thermophilic bacterium Caldicellulosiruptor bescii DSM 6725. Nucleic Acids Res 2011, 39(8):3240-3254.

15. Bayer EA, Shoham Y, Lamed R: Lignocellulose-decomposing bacteria and their enzyme systems. In The Prokaryotes - Prokaryotic Physiology and Biochemistry. Edited by Rosenberg E. Berlin Heidelberg: Springer; 2013:215-266.

16. Zverlov V, Mahr S, Riedel K, Bronnenmeier K: Properties and gene structure of a bifunctional cellulolytic enzyme (CelA) from the extreme thermophile 'Anaerocellum thermophilum' with separate glycosyl hydrolase family 9 and 48 catalytic domains. Microbiology 1998, 144(2):457-465.

17. Chung D, Farkas J, Huddleston JR, Olivar E, Westpheling J: Methylation by a unique alpha-class N4-cytosine methyltransferase is required for DNA transformation of Caldicellulosiruptor bescii DSM6725. PLoS One 2012, 7(8):e43844.

18. Chung D, Farkas J, Westpheling J: Detection of a novel active transposable element in Caldicellulosiruptor hydrothermalis and a new search for elements in this genus. J Indust Microbio Biotech 2013, 40(5):517-521.

19. Clausen A, Mikkelsen MJ, Schroder I, Ahring BK: Cloning, sequencing, and sequence analysis of two novel plasmids from the thermophilic anaerobic bacterium Anaerocellum thermophilum. Plasmid 2004, 52(2):131-138.

20. Chung D, Farkas J, Westpheling J: Overcoming restriction as a barrier to DNA transformation in Caldicellulosiruptor species results in efficient marker replacement. Biotech for Biofuels 2013, 6:82.

21. Chung DH, Huddleston JR, Farkas J, Westpheling J: Identification and characterization of Cbel, a novel thermostable restriction enzyme from Caldicellulosiruptor bescii DSM 6725 and a member of a new subfamily of Haell-like enzymes. J Indust Microbio Biotech 2011, 38(11):1867-1877.

22. Boeke J, LaCroute F, Fink G: A positive selection for mutants lacking orotidine-5'-phosphate decarboxylase activity in yeast: 5-fluoro-orotic acid resistance. Molec General Genetics 1984, 197:345-346.

23. Miroshnichenko ML, Kublanov IV, Kostrikina NA, Tourova TP, Kolganova TV, Birkeland NK, Bonch-Osmolovskaya EA: Caldicellulosiruptor kronotskyensis sp. nov. and Caldicellulosiruptor hydrothermalis sp. nov., two extremely thermophilic, cellulolytic, anaerobic bacteria from Kamchatka thermal springs. Int J Syst Evol Microbiol 2008, 58(Pt 6):1492-1496.

24. Chung D, Cha M, Farkas J, Westpheling J: Construction of a stable replicating shuttle vector for Caldicellulosiruptor species: use for extending genetic methodologies to other members of this genus. PLoS One 2013, 8(5):e62881.

25. O'Sullivan D, Klaenhammer T: Rapid mini-prep isolation of high-quality plasmid DNA from Lacotococcus and Lactobacillus spp. Appl Environ Microbiol 1993, 59(8):2730-2733.

26. Blumer-Schuette SE, Ozdemir I, Mistry D, Lucas S, Lapidus A, Cheng JF, Goodwin LA, Pitluck S, Land ML, Hauser L, Woyke T, Mikhailova N, Pati A Kyrpides NC, Ivanova N, Detter JC, Walston-Davenport K, Han S, Adams MW, Kelly RM: Complete genome sequences for the anaerobic, extremely thermophilic plant biomass-degrading bacteria Caldicellulosiruptor hydrothermalis, Caldicellulosiruptor kristjanssonii, Caldicellulosiruptor kronotskyensis, Caldicellulosiruptor owensensis, and Caldicellulosiruptor lactoaceticus. J Bacteriol 2011, 193(6):1483-1484.

27. Farkas J, Chung D, Cha M, Copeland J, Grayeski P, Westpheling J: Improved growth media and culture techniques for genetic analysis and assessment of biomass utilization by Caldicellulosiruptor bescii. J Indust Microbio Biotech 2013, 40(1):41-49.

28. Donahue JP, Israel DA, Peek RM, Blaser MJ, Miller GG: Overcoming the restriction barrier to plasmid transformation of Helicobacter pylori. Mol Microbiol 2000, 37(5):1066-1074.

29. Johnston C, Martin B, Fichant G, Polard P, Claverys J-PP: Bacterial transformation: distribution, shared mechanisms and divergent control. Nat Rev Microbiol 2014, 12(3):181-196. 
30. Shaw AJ, Hogsett DA, Lynd LR: Natural competence in

Thermoanaerobacter and Thermoanaerobacterium species. Appl Environ Microbiol 2010, 76(14):4713-4719.

31. Lee C, Ow D, Oh S: Quantitative real-time polymerase chain reaction for determination of plasmid copy number in bacteria. J Microbiol Methods 2006, 65:258-267.

doi:10.1186/s13068-014-0132-8

Cite this article as: Groom et al: Heterologous complementation of a pyrF deletion in Caldicellulosiruptor hydrothermalis generates a new host for the analysis of biomass deconstruction. Biotechnology for Biofuels 2014 7:132

\section{Submit your next manuscript to BioMed Central and take full advantage of:}

- Convenient online submission

- Thorough peer review

- No space constraints or color figure charges

- Immediate publication on acceptance

- Inclusion in PubMed, CAS, Scopus and Google Scholar

- Research which is freely available for redistribution 